\title{
"Pengaruh Customer Satisfaction, Brand Trust, dan Customer Feedback Terhadap Customer Loyalty Pada Perusahaan Mobil Suzuki”
}

\author{
ABSTRACT \\ Jhony Putra Satria Arianto, ${ }^{1}$
}

The background of this research to understand the importance of customer satisfaction will result customer loyalty on consumer's of automobile. The design of this research applies a research model based on consumer's of Suzuki Ertiga In Suzuki Indonesia Company which locard in East Bekasi. A total of seventy consumers as respondents were analyzed using multiple regression analysis with SPSS 17. The objectives of this research to examine the importance will result on customer retention and generation of positive word of mouth. The result of this research that the effect of positively Customer Satisfaction, Brand Trust, dan Customer Feedback toward Customer Loyalty. The managerial implication for marketing managers for understanding the importance of customer loyalty to increase company profitability.

\section{Keywords: Customer Satisfaction, Brand Trust, Customer Feedback, Customer Loyalty.}

\section{A. Latar Belakang}

Persaingan yang semakin ketat dan semakin berkembangnya ekspektasi pelanggan mendorong perusahaan untuk lebih memfokuskan pada upaya untuk mempertahankan pelanggan yang ada. Untuk mempertahankan pangsa pasar yang ada melalui pengembangan loyalitas pelanggan merupakan tujuan strategik perusahaan untuk mempertahankan bisnis dan profitabilitas yang diperoleh perusahaan. Loyalitas pelanggan merupakan kunci keberhasilan yang diraih oleh perusahaan. Loyalitas pelanggan dapat menciptakan retensi pelanggan untuk tetap membeli produk atau jasa yang diinginkannya. Berbagai cara perusahaan yang menjual kendaraan bermotor untuk menciptakan loyalitas pelanggan seperti pemberian diskon khusus, keunggulan di dalam fitur dan spesifikasi, berbagai warna yang ditawarkan sehingga pelanggan dapat memilih sesuai dengan yang disenanginya. Apabila terjadi peningkatan kesetiaan konsumen terhadap perusahaan maka dapat meningkatkan pendapatan penjualan melalui peningkatan pembelian dan peningkatan penjualan suatu produk atau layanan jasa (Uncles et al., 2003). Perusahaan yang dapat meningkatkan customer loyalty akan meningkatkan profitabilitas perusahaan melalui produk atau layanan jasa yang dijual dengan adanya pembelian yang dilakukan secara berulang dan adanya rekomendasi dari konsumen terhadap konsumen lainnya mengenai perusahaan atau produk yang dibeli oleh konsumen (Dimitriades, 2006).

Loyalitas pelanggan ditentukan oleh kepuasan pelanggan terhadap suatu merek produk atau jasa (Kiyani dan Niazi, 2012). Kepuasan yang dimiliki oleh pelanggan merupakan perasaan yang timbul setelah pelanggan membandingkan antara apa yang diterima dan harapannya. Fokus dalam memuaskan kebutuhan pelanggan adalah keinginan setiap

\footnotetext{
${ }^{1}$ Penulis adalah pengusaha kelapa sawit, alat berat di Kalimantan Tengah sekligus dosen prodi ekonomi syariah fakultas ekonomi da bisnis Islam IAIN Palangka Raya
} 
perusahaan. Selain faktor penting bagi kelangsungan hidup perusahaan, memuaskan kebutuhan pelanggan dapat meningkatkan keunggulan dalam persaingan. Kepuasan pelanggan timbul karena adanya hasil akumulasi dari konsumen atau pelanggan dalam menggunakan produk dan jasa. Pelanggan puas kalau setelah membeli produk dan menggunakan produk tersebut, ternyata kualitas produknya baik. Oleh karena itu, setiap transaksi atau pengalamam baru, akan memberikan pengaruh terhadap kepuasan pelanggan. Bahkan, pelanggan yang puas akan berbagi rasa dan pengalaman dengan pelanggan lain. Ini akan menjadi referensi bagi perusahaan yang bersangkutan. Oleh karena itu, baik pelanggan maupun produsen akan sama-sama diuntungkan apabila kepuasan terjadi. Pelanggan yang puas terhadap kendaraan bermotor cenderung untuk membeli kembali produk dan menggunakan kembali jasa pada saat kebutuhan yang sama muncul kembali dikemudian hari. Hal ini berarti kepuasan merupakan faktor kunci bagi konsumen dalam melakukan pembelian ulang yang dapat meningkatkan penjualan perusahaan Suzuki. Untuk meningkatkan penjualan perusahaan Suzuki maka perusahaan menjual kendaraan Suzuki Ertiga. Adanya keterkaitan antara kepuasan dengan loyalitas pelanggan. Apabila pelanggan merasa puas maka dapat meningkatkan loyalitas pelanggan (Hafeez dan Muhammad, 2012).

Loyalitas pelanggan ditentukan oleh kepercayaan terhadap suatu merek produk atau jasa (Hsu dan Cai, 2009). Pemahaman mengenai brand trust berbeda dengan kepercayaan interpersonal, karena merek merupakan simbol dan simbol tersebut sulit untuk merespon pelanggan. Untuk memperoleh loyalitas dalam pasar saat ini, pemasar harus memfokuskan pada pembentukan dan pemeliharaan kepercayaan dalam hubungan pelanggan dengan merek. Keinginan pelanggan untuk yakin terhadap sebuah merek dengan resiko-resiko yang dihadapi karena pelanggan memiliki harapan terhadap merek itu akan menyebabkan hasil yang positif. Kepercayaan dapat menciptakan keberhasilan di dalam pembentukan hubungan antara pelanggan dengan perusahaan. Kepercayaan dari dalam diri pelanggan terbentuk dari itikad baik dan kejujuran yang dimiliki oleh seorang pelanggan. Kepercayaan yang dimiliki oleh pelanggan dapat membuat pelanggan ingin membeli produk yang sesuai dengan harapannya. Kepercayaan yang dimiliki oleh pelanggan terhadap merek produk atau jasa merupakan aspek penting di dalam manajemen merek (Matzler, Krauter, dan Bidmon, 2006).

Untuk mempertahankan loyalitas pelanggan maka perusahaan harus lebih inovatif dibandingkan produk atau jasa yang diberikan oleh perusahaan pesaing lainnya. Adapun pesaing yang dihadapi oleh Suzuki Ertiga adalah Toyota Etios, Nissan Grand Livina, Toyota Avanza, dan pesaing lainnya. Inovasi yang dimiliki oleh Suzuki Ertiga hadir dengan transmisi Otomatis (A/T) untuk tipe GL, GX dan GA (M/T), untuk melengkapi jajaran produk mobilmobil suzuki yang ada saat ini, sekaligus memberikan penyegaran dan variasi produk pada segmen pasar kelas MPV Bonnet di tanah air. Mobil ini menggunakan sistem penggerak roda depan (Front Wheel Drive/FWD) dan dengan sasis (Chassis Monocoque) ditambah lagi mesin bensin tipe K-Series terbaru berkapasitas $1.373 \mathrm{cc}$ atau 1,4 liter dan berplatform Suzuki New Swift. Mobil Suzuki Ertiga sebagai kendaraan MPV senyaman sedan, dimana hal tersebut tidak dimiliki oleh kendaraan kompetitor di kelasnya, dan mobil ini sangat cocok sebagai mobil keluarga yang nyaman, aman dan juga tampil gaya atau stylish bagi penggunanya, namun dapat digunakan oleh individu. Dengan berbagai inovasi yang dimiliki oleh Suzuki Ertiga membuat pelanggan untuk tetap membeli mobil tersebut. Ini menunjukkan 
bahwa loyalitas dari dalam diri pelanggan dapat menciptakan keberhasilan bagi perusahaan (Sondoh et al., 2007).

Berdasarkan observasi penulis tersebut, maka penulis tertarik untuk mengkaji mengenai, apakah Customer Satisfaction berpengaruh terhadap Customer Loyalty, apakah Brand Trust berpengaruh terhadap Customer Loyalty, dan apakah Customer Feedback berpengaruh terhadap Customer Loyalty.

\section{B. Customer Satisfaction, Brand Trust, Customer Feedback dan Customer Loyalty}

Kepuasan pelanggan timbul karena pelanggan telah melakukan evaluasi secara positif terhadap suatu produk yang dibelinya (Hafeez dan Muhammad, 2012). Kepuasan pelanggan pun berperan penting di dalam menciptakan loyalitas pelanggan (Mohsan et al., 2011). Kepuasan pelanggan merupakan strategi yang dijalankan oleh perusahaan agar mampu mempertahankan pelanggan dan menarik pelanggan baru (Khattak dan Rehman, 2010). Pelanggan yang memiliki loyalitas tinggi dapat menciptakan rencana pembelian kembali suatu produk atau jasa di masa yang akan datang dan memberikan rekomendasi kepada pelanggan lainnya (Dimitriades, 2006). Kepercayaan yang dimiliki oleh pelanggan dapat menciptakan penilaian baik terhadap kehandalan dari suatu merek produk atau jasa sehingga dapat menciptakan loyalitas pelanggan (Lin dan Lee, 2012). Kepercayaan terhadap suatu merek produk atau jasa yang dijual oleh perusahaan dapat menentukan pengambilan keputusan pembelian dari dalam diri pelanggan (Haefner, Gray, dan Rosenbloom, 2011).

Untuk mempertahankan loyalitas pelanggan, seorang manajer pemasaran berusaha mengumpulkan umpan balik dari dalam diri pelanggan (Neil dan Leotte, 2006). Umpan balik yang diberikan oleh perusahaan dapat memberikan informasi mengenai kinerja dari produk atau jasa yang dijual oleh perusahaan dan kerusakan yang dilaporkan oleh pelanggan harus diperbaiki dengan cepat oleh perusahaan (Swami, 2006). Umpan balik yang diterima dari pelanggan merupakan bentuk layanan purna jual, bentuk pemberian informasi yang disampaikan oleh pelanggan kepada perusahaan, mengatasi keluhan yang timbul dari dalam diri pelanggan yang berdampak pada peningkatan terhadap loyalitas dari dalam diri pelanggan (Dean, 2007). Telah dijelaskan bahwa Customer Satisfaction, Brand Trust, dan Customer Feedback menentukan Customer Loyalty ditunjukkan pada Gambar 1 sebagai berikut:

Gambar 1.

Rerangka Konseptual

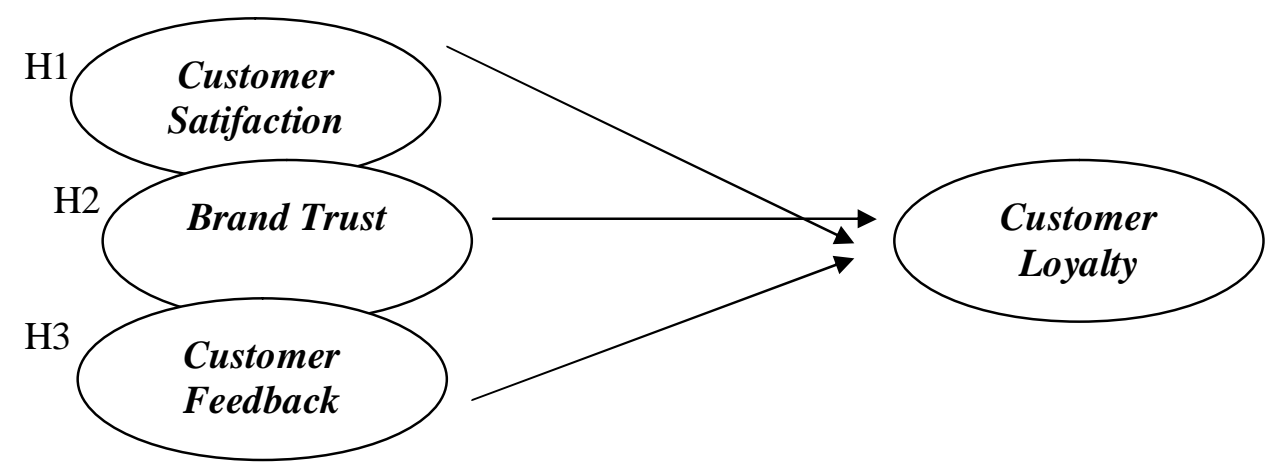


Perumusan Hipotesis

Kepuasan pelanggan dipertimbangkan sebagai faktor penting di dalam pembentukan loyalitas pelanggan (Kotler dan Keller, 2008). Kepuasan yang dimiliki oleh seorang pelanggan dapat dinilai setelah pelanggan melakukan konsumsi suatu produk atau jasa (Suzana, Sanja, dan Klaudio, 2010). Kepuasan dari dalam diri pelanggan merupakan tujuan yang dimiliki oleh perusahaan dalam menjalankan bisnisnya (Hansemark dan Albinsson, 2004). Loyalitas yang dimiliki oleh seorang pelanggan dapat meningkatkan pendapatan dan profitabilitas perusahaan (Castaneda, 2011). Kepuasan pelanggan timbul karena seorang pelanggan merasa senang dengan kinerja produk atau jasa yang dibelinya sehingga dapat memenuhi harapan yang dimiliki oleh pelanggan sehingga pelanggan memiliki keinginan untuk meningkatkan frekuensi pembelian suatu produk atau jasa (Santouridis dan Trivellas, 2010). Loyalitas pelanggan merupakan perilaku dari dalam diri pelanggan yang disukai oleh perusahaan karena dengan loyalitas pelanggan dapat menciptakan perilaku pembelian berulang di masa yang akan datang (Dimitriades, 2006). Adapun hipotesis penelitian dinyatakan sebagai berikut:

H1 : Customer Satisfaction berpengaruh positif terhadap Customer Loyalty.

Kepercayaan yang dimiliki oleh seorang penting merupakan faktor penting bagi perusahaan dalam menjalankan bisnis (Liu dan Zhang, 2010). Kepercayaan yang dimiliki oleh pelanggan merupakan asset yang tidak berwujud dapat diperoleh perusahaan (Matzler, Krauter, dan Bidmon, 2006). Kepercayaan dari dalam diri pelanggan ditunjukkan dengan adanya keyakinan dari seorang pelanggan terhadap kehandalan dan integritas yang dimiliki oleh perusahaan ketika menjual suatu produk atau jasa (Zboja dan Voorhees, 2006). Kepercayaan yang dimiliki oleh pelanggan dapat menciptakan loyalitas pelanggan karena pelanggan memiliki pengalaman yang baik terhadap perusahaan seperti adanya nilai kejujuran dan keadilan yang dimiliki oleh perusahaan dalam menjual produk atau jasa (Lin dan Lee, 2012). Adapun hipotesis penelitian dinyatakan sebagai berikut:

H 2: Brand Trust berpengaruh positif terhadap Customer Loyalty.

Umpan balik yang disampaikan oleh pelanggan timbul karena pelanggan memiliki keluhan ketika pelanggan menjalin hubungan dalam jangka panjang dengan perusahaan (Bell dan Ludington, 2006). Seorang pelanggan biasanya memberikan umpan balik secara langsung berupa informasi mengenai keluhan yang dimilikinya terhadap karyawan (Lovelock dan Wirtz, 2007). Umpan balik yang diberikan oleh seorang pelanggan dapat menciptakan aktivitas pengembangan dan perbaikan terhadap produk atau jasa yang dijual oleh perusahaan (Haverila dan Naumann, 2010). Adapun hipotesis penelitian dinyatakan sebagai berikut:

H3 : Customer Feedback berpengaruh positif terhadap Customer Loyalty.

\section{Pengaruh Customer Satisfaction, Brand Trust, dan Customer Feedback Terhadap Customer Loyalty Pada Perusahaan Mobil Suzuki}

Statistik deskriptif adalah statistik yang menggambarkan fenomena atau karakteristik dari data yang diteliti dalam suatu situasi (Sekaran, 2006). Statistik deskriptif adalah suatu 
deskripsi mengenai pengumpulan, penyusunan, serta penyajian data berdasarkan nilai ratarata (Mean) (Santoso, 2008). Hasil statistik dari variabel-variabel Customer Satisfaction, Brand Trust, Customer Feedback, dan Customer Loyalty dapat dilihat pada Tabel 4 di bawah ini :

\section{Tabel 4.}

Statistik Deskriptif

\begin{tabular}{lccc}
\multicolumn{1}{c}{ Statistik Deskriptif } & \\
\hline \multicolumn{1}{c}{ Variabel } & $\mathbf{n}=\mathbf{7 0}$ & Mean & Std. Deviation \\
& & & \\
\hline $\begin{array}{l}\text { Customer } \\
\text { Satisfaction } \\
\text { Brand Trust }\end{array}$ & 70 & 3,96 & 0,57 \\
& 70 & 3,89 & 0,60 \\
Customer Feedback & 70 & 3,84 & 0,60 \\
& 70 & & 0,53 \\
Customer Loyalty & & 3,85 & \\
& & & \\
\hline
\end{tabular}

Nilai rata-rata (mean) yang paling tinggi dari pembentukan tanggapan terhadap Customer Satisfaction diperoleh nilai rata-rata sebesar 3,96 maka menunjukkan responden cenderung berpendapat bahwa mobil Suzuki Ertiga sangat memenuhi harapan saya dengan standar deviasi sebesar 0,57 . Nilai rata-rata yang paling rendah dari pembentukan tanggapan terhadap Customer Feedback diperoleh nilai rata-rata sebesar 3,84 maka menunjukkan responden cenderung berpendapat bahwa perusahaan mengumpulkan informasi mengenai umpan balik yang dimiliki oleh pelanggan dengan standar deviasi sebesar 0,60. Nilai rata-rata dari pembentukan tanggapan terhadap Brand Trust diperoleh nilai rata-rata sebesar 3,89 maka menunjukkan responden cenderung berpendapat bahwa saya yakin ketika saya melakukan evaluasi kepada perusahaan yang menjual mobil Suzuki Ertiga dengan standar deviasi sebesar 0,60. Nilai rata-rata dari pembentukan tanggapan terhadap Customer Loyalty diperoleh nilai rata-rata sebesar 3,85 maka menunjukkan responden cenderung berpendapat bahwa saya menggunakan mobil Suzuki Ertiga karena pilihan yang tepat untuk saya dengan standar deviasi sebesar 0,53 . 


\section{Hasil Uji Hipotesis}

Tabel 5.

Hasil Uji Hipotesis

\begin{tabular}{lccc}
\hline \multicolumn{1}{c}{ Hipotesis } & $\begin{array}{c}\text { Standardized } \\
\text { Coefficient } \\
\text { Beta }(\boldsymbol{\beta})\end{array}$ & p-value & Keputusan \\
\hline $\begin{array}{l}\mathrm{H}_{1}: \text { Customer } \\
\text { Satisfaction } \\
\text { Customer Loyalty }\end{array}$ & 0,330 & 0,006 & $\begin{array}{c}\mathrm{Ho}_{1} \text { ditolak, } \\
\mathrm{Ha}_{1} \text { diterima }\end{array}$ \\
$\begin{array}{l}\mathrm{H}_{2}: \text { Brand Trust } \\
\text { Customer Loyalty }\end{array}$ & 0,293 & 0,007 & $\mathrm{Ho}_{2}$ ditolak, \\
$\begin{array}{l}\mathrm{H}_{3}: \text { Customer } \\
\text { Feedback } \\
\text { Customer Loyalty }\end{array}$ & 0,255 & 0,018 & $\mathrm{Ho}_{3}$ ditolak, \\
\hline
\end{tabular}

Hipotesis 1:

Bunyi hipotesis null (H0) dan hipotesis alternatif (Ha) adalah sebagai berikut: Loyalty.

H01: Customer Satisfaction tidak memiliki pengaruh positif terhadap Customer

Ha1: Customer Satisfaction memiliki pengaruh positif terhadap Customer Loyalty.

Pada pengujian hipotesis 1 diketahui p-value $0,006<$ alpha 0,05 dengan nilai beta sebesar 0,330 maka H01 ditolak dan Ha1 diterima yang artinya Customer Satisfaction memiliki pengaruh positif terhadap Customer Loyalty. Dengan adanya peningkatan terhadap kepuasan pelanggan maka dapat menciptakan loyalitas pelanggan. Hal ini ditunjukkan dengan saya merasa puas ketika melakukan evaluasi terhadap mobil Suzuki Ertiga sehingga saya menggunakan mobil Suzuki Ertiga karena pilihan yang tepat untuk saya.

Hipotesis 2:

Bunyi hipotesis null (H0) dan hipotesis alternatif (Ha) adalah sebagai berikut:

H02: $\quad$ Brand Trust tidak memiliki pengaruh positif terhadap Customer Loyalty.

Ha2: $\quad$ Brand Trust memiliki pengaruh positif terhadap Customer Loyalty.

Pada pengujian hipotesis 2 diketahui p-value $0,007<$ alpha 0,05 dengan nilai beta sebesar 0,293 maka H02 ditolak dan Ha2 diterima yang artinya Brand Trust memiliki pengaruh positif terhadap Customer Loyalty. Dengan keyakinan dari diri pelanggan terhadap produk atau jasa yang dijual oleh perusahaan dapat menciptakan loyalitas pelanggan. Hal ini ditunjukkan dengan saya yakin ketika saya melakukan evaluasi kepada perusahaan yang menjual mobil Suzuki Ertiga sehingga saya menggunakan mobil Suzuki Ertiga karena pilihan yang tepat untuk saya.

Hipotesis 3:

Bunyi hipotesis null (H0) dan hipotesis alternatif (Ha) adalah sebagai berikut:

H03: Customer Feedback tidak memiliki pengaruh positif terhadap Customer Loyalty.

Ha3: Customer Feedback memiliki pengaruh positif terhadap Customer Loyalty. 
Pada pengujian hipotesis 3 diketahui p-value $0,018<$ alpha 0,05 dengan nilai beta sebesar 0,255 maka H03 ditolak dan Ha3 diterima yang artinya Customer Feedback memiliki pengaruh positif terhadap Customer Loyalty. Dengan umpan balik yang diberikan oleh pelanggan kepada perusahaan dapat menciptakan loyalitas pelanggan. Hal ini ditunjukkan dengan adanya perusahaan mengumpulkan informasi mengenai umpan balik yang dimiliki oleh pelanggan sehingga saya menggunakan mobil Suzuki Ertiga karena pilihan yang tepat untuk saya.

Pembahasan Hasil Penelitian

Pada Tabel 5 terlihat pada hasil yang menguji tiga hipotesis penelitian bahwa Customer Satisfaction memiliki pengaruh positif terhadap Customer Loyalty, Brand Trust memiliki pengaruh positif terhadap Customer Loyalty, dan Customer Feedback memiliki pengaruh positif terhadap Customer Loyalty. Adapun pembahasan dari masing-masing hipotesis penelitian sebagai berikut :

\section{Hipotesis 1: Customer Satisfaction memiliki pengaruh positif terhadap Customer Loyalty.}

Kepuasan pelanggan adalah tingkat perasaan pelanggan setelah membandingkan antara apa yang diterima dan harapannya. Seorang pelanggan, jika merasa puas dengan nilai yang diberikan oleh produk atau jasa, sangat besar kemungkinannya menjadi pelanggan dalam waktu yang lama. Kepuasan pelanggan adalah keinginan setiap perusahaan. Selain faktor penting bagi kelangsungan hidup perusahaan, memuaskan kebutuhan konsumen dapat meningkatkan keunggulan dalam persaingan. Pelanggan yang puas terhadap produk dan jasa pelayanan cenderung untuk membeli kembali produk dan menggunakan kembali jasa pada saat kebutuhan yang sama muncul kembali dikemudian hari. Hal ini berarti kepuasan merupakan faktor kunci bagi konsumen dalam melakukan pembelian ulang yang merupakan porsi terbesar dari volume penjualan perusahaan. Dengan perasaan puas terhadap produk atau jasa yang dijual oleh perusahaan dapat menciptakan Loyalitas pelanggan. Loyalitas pelanggan timbul karena kedalaman komitmen untuk tetap membeli produk atau jasa yang dijual oleh perusahaan. Kedalaman komitmen menunjukkan adanya kesetiaan yang timbul dari dalam diri pelanggan tanpa adanya paksaan orang lain untuk tetap membeli produk atau jasa. Loyalitas pelanggan diharapkan perusahaan akan mendapatkan keuntungan jangka panjang atas hubungan yang saling menguntungkan terjalin dalam kurun waktu tertentu.

Pada pengujian hipotesis 1 diketahui p-value $0,006<$ alpha 0,05 dengan nilai beta sebesar 0,330 maka H01 ditolak yang artinya Customer Satisfaction memiliki pengaruh positif terhadap Customer Loyalty. Dengan adanya peningkatan terhadap kepuasan pelanggan maka dapat menciptakan loyalitas pelanggan. Hal ini ditunjukkan dengan saya merasa puas ketika melakukan evaluasi terhadap mobil Suzuki Ertiga sehingga saya menggunakan mobil Suzuki Ertiga karena pilihan yang tepat untuk saya. Hasil penelitian ini mendukung hasil penelitian yang dilakukan oleh Kiyani dan Niazi (2012). Di dalam penelitian Kiyani dan Niazi (2012) ditunjukkan bahwa besarnya pengaruh positif Customer Satisfaction terhadap Customer Loyalty diperoleh nilai beta sebesar 0,845 dan nilai signifikan kurang dari 0,01 $(\beta=0,845 ; p$-value $<0,01)$. 


\section{Hipotesis 2: Brand Trust memiliki pengaruh positif terhadap Customer Loyalty.}

Dalam kondisi persaingan yang seekarang ini, setiap perusahaan harus mampu bertahan hidup, bahkan harus dapat terus berkembang. Salah satu hal penting yang perlu dilakukan dan diperhatikan oleh setiap perusahaan adalah mempertahankan pelanggan yang telah ada, terus menggarap pelanggan-pelanggan potensial baru agar jangan sampai pelanggan meninggalkan perusahaan menjadi pelanggan perusahaan lain. Dengan kata lain perusahaan harus mampu mempertahankan loyalitas pelanggan. Loyalitas pelanggan terhadap merek produk merupakan konsep yang sangat penting khususnya pada kondisi tingkat persaingan yang sangat ketat dengan pertumbuhan yang rendah. Pada kondisi demikian loyalitas pada merek sangat dibutuhkan agar perusahaan dapat bertahan hidup. Di samping itu, upaya mempertahankan loyalitas merek ini merupakan upaya strategis yang lebih efektif dibandingkan dengan upaya menarik pelanggan baru. Persoalan merek menjadi salah satu persoalan yang harus dipantau secara terus menerus oleh setiap perusahaan. Kepercayaan yang dimiliki oleh pelanggan terhadap merek produk atau jasa yang dijual oleh perusahaan dapat menciptakan loyalitas pelanggan.

Pada pengujian hipotesis 2 diketahui p-value $0,007<$ alpha 0,05 dengan nilai beta sebesar 0,293 maka H02 ditolak yang artinya Brand Trust memiliki pengaruh positif terhadap Customer Loyalty. Dengan keyakinan dari diri pelanggan terhadap produk atau jasa yang dijual oleh perusahaan dapat menciptakan loyalitas pelanggan. Hal ini ditunjukkan dengan saya yakin ketika saya melakukan evaluasi kepada perusahaan yang menjual mobil Suzuki Ertiga sehingga saya menggunakan mobil Suzuki Ertiga karena pilihan yang tepat untuk saya. Hasil penelitian ini mendukung hasil penelitian yang dilakukan oleh Kiyani dan Niazi (2012). Di dalam penelitian Kiyani dan Niazi (2012)ditunjukkan bahwa besarnya pengaruh positif Brand Trust terhadap Customer Loyalty diperoleh nilai beta sebesar 0,657 dan nilai signifikan kurang dari $0,01(\beta=0,657$; p-value $<0,01)$.

\section{Hipotesis 3: Customer Feedback memiliki pengaruh positif terhadap Customer Loyalty.}

Kebutuhan dan keinginan konsumen atau pelanggan pun biasanya sangat beragam dan terus berubah sesuai dengan waktu dan keadaan. Itu sebabnya penting sekali perusahaan mendapatkan umpanbalik (feedback) dari pelanggan mengenai kebutuhan, keinginan dan masukan dari pelanggan mengenai produk atau jasa yang ditawarkan. Seringkali informasi dari pelanggan merupakan ide-ide cemerlang untuk kemajuan produk dan layanan perusahaan. Memang tidak mudah untuk mendapatkan umpan balik dari pelanggan, seringkali kotak saran yang disediakan di toko atau perusahaan hanya sekedar pajangan yang dibiarkan kosong. Diperlukan teknik-teknik khusus untuk hal ini. Berikut teknik untuk mendapatkan umpan balik dari pelanggan seperti aktif bertanya, survei dan kuesioner, penghargaan terhadap responden, berikan produk atau jasa secara gratis kepada pelanggan, membuat komunitas pencinta merek produk atau jasa, hubungan baik dengan pelanggan. Dengan umpan balik yang diberikan oleh pelanggan dapat menciptakan loyalitas dari dalam diri pelanggan terhadap produk atau jasa yang dijual oleh perusahaan. 
Pada pengujian hipotesis 3 diketahui p-value $0,018<$ alpha 0,05 dengan nilai beta sebesar 0,255 maka H03 ditolak yang artinya Customer Feedback memiliki pengaruh positif terhadap Customer Loyalty. Dengan umpan balik yang diberikan oleh pelanggan kepada perusahaan dapat menciptakan loyalitas pelanggan. Hal ini ditunjukkan dengan adanya perusahaan mengumpulkan informasi mengenai umpan balik yang dimiliki oleh pelanggan sehingga saya menggunakan mobil Suzuki Ertiga karena pilihan yang tepat untuk saya. Hasil penelitian ini mendukung hasil penelitian yang dilakukan oleh Dean (2007). Di dalam penelitian Dean (2007) ditunjukkan bahwa besarnya pengaruh positif Customer Feedback terhadap Customer Loyalty diperoleh nilai beta sebesar 0,86 dan nilai signifikan kurang dari $0,001(\beta=0,86 ; p$-value $<0,001)$.

\section{PENUTUP}

Berdasarkan uraian dan analisis yang telah dikemukakan pada bab sebelumnya, maka simpulan yang diperoleh dari penelitian ini adalah: Customer Satisfaction memiliki pengaruh positif terhadap Customer Loyalty. Dengan adanya peningkatan terhadap kepuasan pelanggan maka dapat menciptakan loyalitas pelanggan. Hal ini ditunjukkan dengan saya merasa puas ketika melakukan evaluasi terhadap mobil Suzuki Ertiga sehingga saya menggunakan mobil Suzuki Ertiga karena pilihan yang tepat untuk saya.

\section{DAFTAR PUSTAKA}

Colwell, S., Sandra Hogarth-Scott, Depeng Jiang, Ashwin Joshi, (2009), "Effects of organizational and serviceperson orientation on customer loyalty", Management Decision, Vol. 47 Iss: 10, pp.1489-1513.

Dimitriades, Z.S. (2006), "Customer satisfaction, loyalty and commitment in service organizations: Some evidence from Greece”, Management Research News, Vol. 29 No. 12 , pp.782-800.

Haefner, J. E., Deli-Gray, Z., \& Rosenbloom, A. (2011), “The importance of brand liking and brand trust in consumer decision making: Insights from Bulgarian and Hungarian consumers during the global economic crisis", Managing Global Transitions: International Research Journal, Vol. 9 No.3, pp.249-273.

Hafeez, S., \& Hasnu, S. (2010), "Customer satisfaction for cellular phone in Pakistan: A case study of Mobilink”, Business and Economics Research Journal, Vol.1 No.(3), pp. 35-44.

Hafeez, S. and Muhammad, B. (2012), "The Impact of Service Quality, Customer Satisfaction and Loyalty Programs on Customer's Loyalty: Evidence from Banking Sector of Pakistan”, International Journal of Business and Social Science ,Vol.3 No.16, pp. 200-209.

Hahn, K.H. and Kim, J. (2009), "The effect of offline brand trust and perceived internet confidence on online shopping intention in the integrated multi-channel context", International Journal of Retail \& Distribution Management, Vol.37 No.2, pp. (2009): 126-141.

Hansemark, O.C. and Albinsson, M. (2004) "Customer satisfaction and retention: the experiences of individual employees", Managing Service Quality, Vol. 14 No. 1, pp.40 -57 . 
Hsu, C. and Cai, L.A. (2009), "Brand Knowledge, Trust and Loyalty - A Conceptual Model of Destination Branding", International CHRIE-Conference-Refereed Track, Vol.12, pp.1-8.

Jamal, A. and Naser, K. (2002), "Customer satisfaction and retail banking: an assessment of some of the key antecedents of customer satisfaction in retail banking", International Journal of Bank Marketing, Vol. 20 Iss: 4, pp.146-160.

Kiyani, T.M. and Niazi, K.U.R.M. (2012), “The Relationship Between Brand Trust, Customer Satisfaction, And Customer Loyalty:Evidence From Automobile Sector Of Pakistan", Interdisclipinary Journal of Contemporary Research In Business, Vol. 4 No.1, pp. 489.

Li, D., Browne, G. J., and Chau, P. Y. K. 2006. "An Empirical Investigation of Web Site Use Using a Commitment-Based Model,” Decision Sciences (37:3), pp. 427-444.

Lin, M.Q. and Lee, B.C.Y. (2012), "The influence of website environment on brand Loyalty: Brand Trust and Brand Affect as Mediators", International Journal of Electronic Business Management, Vol. 10, No. 4, pp. 308-321.

Matzler, K., Bidmon, S., and Grabner-Kräuter, S. (2006) "Individual determinants of brand affect: the role of the personality traits of extraversion and openness to experience", Journal of Product \& Brand Management, Vol. 15 No. 7, pp.427 - 434.

Matzler, Kurt; Sonja Grabner-Kräuter; Bidmon, Sonja. (2008), "Risk aversion and brand loyalty: the mediating role of brand trust and brand affect", The Journal of Product and Brand Management, Vol. 17 No.3, pp. 154-162.

Mishra, A. A. (2009), "A study on Customer Satisfaction in Indian Retail Banking”, IUP Journal of Management Research, Vol. 8 No.(11), pp. 45-61.

Mohamed, Rozita Naina; Norzaidi Mohd Daud. (2012), "The impact of religious sensitivity on brand trust, equity and values of fast food industry in Malaysia", Business Strategy Series, Vol.13 No.1, pp. 21-30.

Molina, A., Martin-Consuegra, D., and Esteban, A. (2007), "Relational Benefits and Customer Satisfaction in Retail Banking", International Journal of Business Marketing, Vol.25 No.(4), pp. 253-271.

Naumann, E., Haverila, M., Khan, S., \& Williams, P. (2010), "Understanding the Causes of Defection Among Satisfied B2B Service Customers", Journal of Marketing Management, Vol.26(9-10).

Soderlund, M. and Rosengren, S. (2008), "Revisiting the smiling service worker and customer satisfaction", International Journal of Service Industry Management, Vol. 19 Iss: 5, pp.552-574.

Sondoh, S.L., Omar, M.W., Wahid, N.A., Ismail, I. \& Haru, A. (2007), "The Effect of Brand Image on Overall Satisfaction and Loyalty Intention in the Context of Color Cosmetic", Journal Asian Academy of Management, Vol.12 No.(1), pp. 83-107.

Uncles, M.D., Dowling, G. R., and Hammond, K. (2003), "Customer Loyalty and Customer Loyalty Programs”, Journal of Consumer Marketing, Vol. 20 No. 4, pp. 294-316.

Wang, C.Y. and Wu, L.W. (2012), "Customer loyalty and the role of relationship length", Managing Service Quality, Vol. 22 No. 1, pp.58-74. 
Wirtz, J. and Chew, P. (2002) "The effects of incentives, deal proneness, satisfaction and tie strength on word-of-mouth behavior", International Journal of Service Industry Management, Vol. 13 Iss: 2, pp.141-162. 